\title{
Biodiversity effects of the predation gauntlet
}

\author{
Adrian C. Stier ${ }^{1} \cdot$ Christopher D. Stallings $^{2} \cdot$ Jameal F. Samhouri $^{3}$ • \\ Mark A. Albins ${ }^{4}$ - Glenn R. Almany ${ }^{5,6}$
}

Received: 17 July 2016/ Accepted: 8 January 2017

(c) Springer-Verlag Berlin Heidelberg 2017

\begin{abstract}
The ubiquity of trophic downgrading has led to interest in the consequences of mesopredator release on prey communities and ecosystems. This issue is of particular concern for reef-fish communities, where predation is a key process driving ecological and evolutionary dynamics. Here, we synthesize existing experiments that have isolated the effects of mesopredators to quantify the role of predation in driving changes in the abundance and biodiversity of recently settled reef fishes. On average, predators reduced prey abundance through generalist foraging behavior, which, through a statistical sampling artifact, caused a reduction in alpha diversity and an increase in beta diversity. Thus, the synthesized experiments provide
\end{abstract}

Communicated by Ecology Editor Dr. Michael Berumen

Electronic supplementary material The online version of this article (doi:10.1007/s00338-017-1544-2) contains supplementary material, which is available to authorized users.

Adrian C. Stier

adrian.stier@lifesci.ucsb.edu

1 Department of Ecology, Evolution, and Marine Biology, University of California, Santa Barbara, CA 93106, USA

2 College of Marine Science, University of South Florida, 140 7th Ave S, St. Petersburg, FL 33701, USA

3 Conservation Biology Division, Northwest Fisheries Science Center, National Marine Fisheries Service, National Oceanic and Atmospheric Administration, Seattle, WA 98112, USA

4 Department of Marine Sciences, University of South Alabama, Dauphin Island Sea Lab, Dauphin Is, AL 36528, USA

5 EPHE, PSL Research University, UPVD-CNRS, USR3278 CRIOBE, 66360 Perpignan, France

6 Laboratoire d'Excellence 'CORAIL', Perpignan, France evidence that predation reduces overall abundance within prey communities, but-after accounting for sampling effects-does not cause disproportionate effects on biodiversity.

Keywords Predator-prey · Rarefaction - Coral reef - Reef fish · Assembly · Invasive predators

\section{Introduction}

Declines in apex predator populations can cause irruptions in the abundance and shifts in the behavior of previously suppressed mesopredators (Prugh et al. 2009). This trophic 'release' of mesopredators is cause for conservation concern, because when abundant, they can cause extinctions and major shifts in ecosystem function (Crooks and Soulé 1999; Ritchie and Johnson 2009). The reduction of apex predators and subsequent mesopredator release is a widespread phenomenon across ecosystems (Estes et al. 2011) and is particularly prevalent in coral-reef ecosystems due to disproportionately high fishing rates at the top of the food chain (Stallings 2009; DeMartini and Smith 2015). Abundance of coral-reef mesopredators (e.g., small-bodied groupers and snappers) has also increased through the introduction of non-native predators. In some cases, these introduced predators have become extremely successful, for example, the intentionally introduced peacock grouper (Cephalopholis argus) in Hawaii (Meyer and Dierking 2011) and the accidentally introduced Pacific lionfishes (Pterois volitans and Pterois miles) in the Atlantic and Caribbean (Côté et al. 2013) have each become numerically dominant mesopredators in their respective invaded communities. Because predation is known to be a key driver of ecosystem and evolutionary dynamics (Hixon 
1991, 2015), these fishing- and invasion-associated shifts in the abundance and biomass of predators are considered cause for concern among coral-reef managers and conservation practitioners. Settling fishes experience extraordinarily high predation rates on coral reefs (Almany and Webster 2006), with an average of $50 \%$ mortality in their first $48 \mathrm{~h}$ on the reef (i.e., a 'predation gauntlet'). This effect of predators declines rapidly with increases in prey body size (Sogard 1997; Goatley and Bellwood 2016). Thus, increases in mesopredator abundance have the capacity to drive major shifts in the abundance and biodiversity of coral-reef fish communities by amplifying the intensity of the predation gauntlet.

Mesopredator effects have historically been difficult to quantify on coral reefs, because these predators often positively covary in abundance and diversity with their prey due to shared reef habitat (Stier et al. 2014). Therefore, only a handful of field experiments have been able to isolate the role of mesopredators in altering prey community size and composition (Hixon 2015). Here, we conducted a metaanalysis of all (to our knowledge) published predation experiments to quantify the extent to which mesopredators affect prey abundance and biodiversity in coral-reef fishes. We focused on three distinct aspects of biodiversity including gamma diversity (species richness at the study scale), alpha diversity (species richness at the sample scale), and beta diversity (a measure of the spatial variability of community composition among samples across the study). We also used rarefaction methods to calculate corrected alpha and beta diversity measures by accounting for the effects of abundance on biodiversity. We then compared the effects of native mesopredators to those of invasives (peacock grouper and lionfish) and briefly identified two opportunities for future research on reef-fish predator-prey dynamics.

\section{Methods}

\section{Focal experiments}

We quantified the effects of reef-fish mesopredators on prey abundance and biodiversity in ten published studies 2002-2014 (Electronic supplementary material, ESM, Table S1). We identified these ten focal studies using extensive Google Scholar and ISI Web of Science literature searches from 1990 to 2016 in major ecological and marine journals using all combinations of the following keywords: predation, coral reef fish, predation gauntlet, reef fish, community assembly, and depredation. Each of these ten studies was conducted with similar methods, where isolated experimental reefs were constructed in sandy environments. Prey communities were manipulated prior to each study either through the removal of all prey or through the selective removal of all recently recruited individuals. Predators were then manipulated on a subset of the patch reefs through selective additions and removals or cages; then, new prey communities were allowed to recruit to reefs with different predator treatments (control $=$ predators absent, treatment $=$ predators present). Predator manipulations were pressed in all studies (i.e., unwanted predators on control treatments were removed and predator-present treatments were maintained). Prey communities were visually surveyed by divers on a regular basis over a period of time that ranged from 42 to $120 \mathrm{~d}$. Additional study details including predator species, duration, and additional manipulations of other variables such as adult damselfish abundance and habitat complexity (additional known drivers of reef-fish community assembly) can be found in ESM Table S1.

\section{Measuring prey community response}

We compared recruiting prey communities in experimental treatments with and without predators using five different response variables: (1) total abundance of all prey species; (2) gamma diversity measured as the species list on reefs with and without predators (i.e., the total number of prey species found in control or predator-present treatments); (3) alpha diversity measured as the number of species within a patch; (4) rarefied alpha diversity (the number of species within a patch, corrected for abundance); (5) beta diversity based on species incidence (the Jaccard index: a metric focused on the gain or loss of a species); and (6) rarefied beta diversity (Jaccard index corrected for differences in abundance). We quantified beta diversity in predator and no-predator treatments by estimating the median multivariate dispersion around the multivariate centroid of the community (Anderson et al. 2006).

\section{Rarefaction}

Communities with higher abundance tend to have higher alpha diversity and lower beta diversity (Gotelli and Colwell 2001; Cardoso et al. 2009; Stier et al. 2016). Because alpha diversity is often strongly correlated with abundance, predation can reduce observed alpha diversity and increase observed beta diversity simply because it causes a decline in the number of prey individuals (Fig. 1a, b). We used individual-based rarefaction to estimate rarefied alpha (Gotelli and Colwell 2001) and beta diversity (Stier et al. 2014) because control treatments tended to have a higher abundance than those with predators. Predator-induced reductions in rarefied diversity implicate biological process(es) rather than a statistical sampling artifact (Fig. 1c).

We define generalist predators as those that affect prey species in proportion to prey abundance. If predators eat prey in proportion to their abundance, rarefied alpha and 

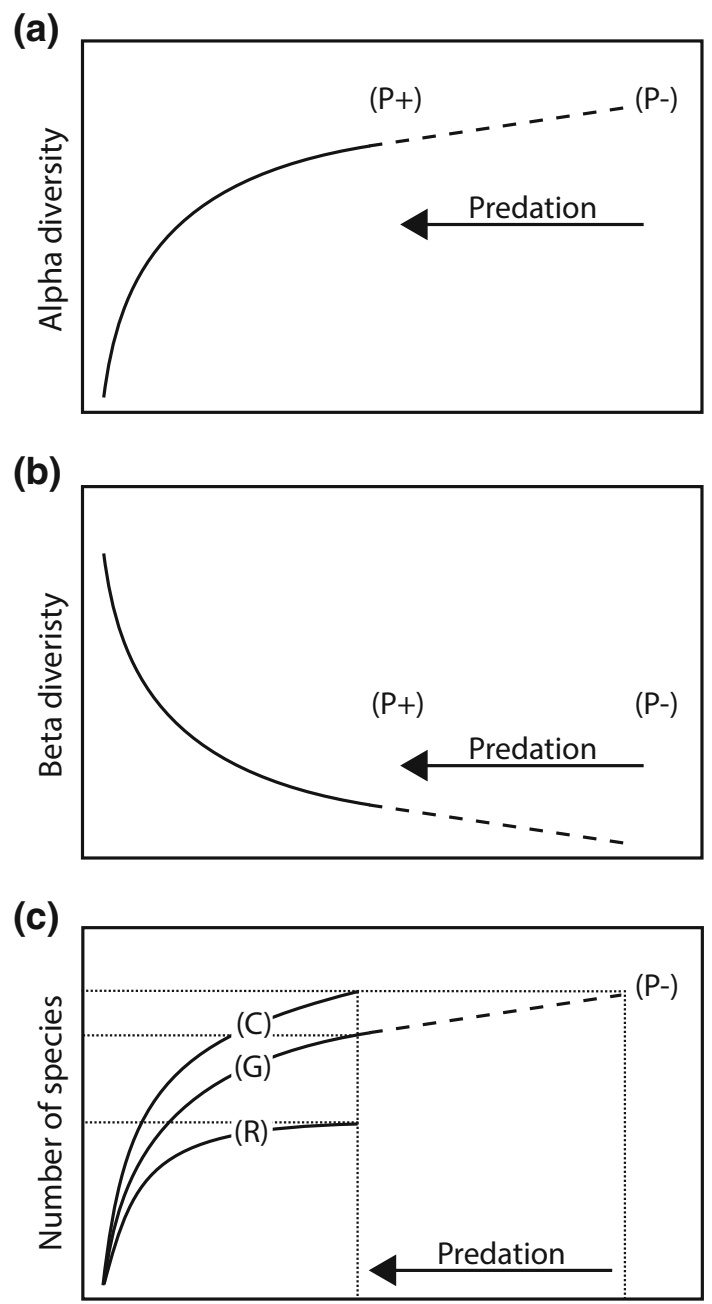

Number of individuals

Fig. 1 When predators reduce abundance, alpha diversity should decrease and beta diversity should increase. This effect can provide insight into expected effects of predators on alpha and beta diversity through reductions in abundance (see arrow). Panels illustrate individual-based rarefaction curves (a alpha diversity, b beta diversity). Rarefaction of alpha diversity can be used to gain insights into whether predators disproportionately affect common or rare species. c Three different individual-based rarefaction curves that might emerge from different predator effects. A patch that has no predators will have a rarefaction curve labeled $P$-. The manner in which reduced abundance by predators affects species richness depends on whether predators are generalists or whether they disproportionately affect common or rare species. If predators affect species in proportion to their abundance (i.e., generalists), they will have rarefaction curve G. If predators disproportionately affect common species, they will have a greater number of species per individual compared to generalist predators (curve C), and if predators disproportionately affect rare species, they will produce rarefaction curve $\mathrm{R}$, decreasing diversity relative to generalist predators

beta diversity should remain the same across predator and control treatments. If predators disproportionately consume common or rare species or alter competitive dynamics, differences in alpha and beta diversity will emerge for rarefied indices. The mesopredators involved in our metaanalysis are considered generalists though this has not been previously assessed quantitatively. For additional details on rarefaction, see ESM 2 and Stier et al. (2013b, 2014).

\section{Effect sizes}

We estimated the effect of predators $(P+)$ relative to predator-free controls $(P-)$ for each study using the logresponse ratio (Osenberg et al. 1999):

$\mu_{i}=\log \left(\frac{P_{i}+}{P_{i}-}\right)$,

where $\mu_{i}$ is the predation effect size, and $P_{i}+$ and $P_{i}-$ represent the abundance, alpha diversity, or beta diversity of prey in the presence and absence of predators, respectively, for the $i$ th study.

Variance of the effect size was estimated using the delta method:

$\operatorname{var}\left(\mu_{i}\right)=\frac{\operatorname{var}\left(P_{i}-\right)}{\left(P_{i}-\right)^{2}}+\frac{\operatorname{var}\left(P_{i}+\right)}{\left(P_{i}+\right)^{2}}$.

For abundance, alpha diversity, and beta diversity, we tested the hypothesis that the effect size differed from zero and estimated nonparametric bootstrapped confidence intervals using a random-effects model implemented in the metafor package in R (Viechtbauer 2010). We weighted studies by the inverse of the sampling variance of their effect sizes, as recommended by Hedges et al. (1999), to account for greater certainty in studies with less variation. However, there was no variance estimate for gamma diversity; therefore, we used a $t$ test to compare the effect size to zero. We assumed that the response of each community was statistically independent. Experiments exhibited minor overlap in predator species; however, individual experiments had limited temporal overlap, suggesting prey recruitment events were largely independent. All analyses were made using the $\mathrm{R}$ statistical programming environment (R Development Core Team 2013).

\section{Results and discussion}

Mesopredators had substantial effects on prey abundance and biodiversity. Across the ten focal studies, prey communities on reefs with mesopredators had $60 \%$ lower abundance $(Q=82.616, d f=10, P<0.001$; Figs. 2, 3a) and an average of $35 \%$ lower gamma diversity $(t=2.711$, $d f=10, P=0.022$; ESM Fig. S1). This reduction in gamma diversity was primarily driven by the $36 \%$ average reduction in alpha diversity $(Q=82.615, d f=10$, $P=0.001$; Fig. 3b). However, there was no detectable effect of mesopredators on rarefied alpha diversity $(0.1 \%$ 


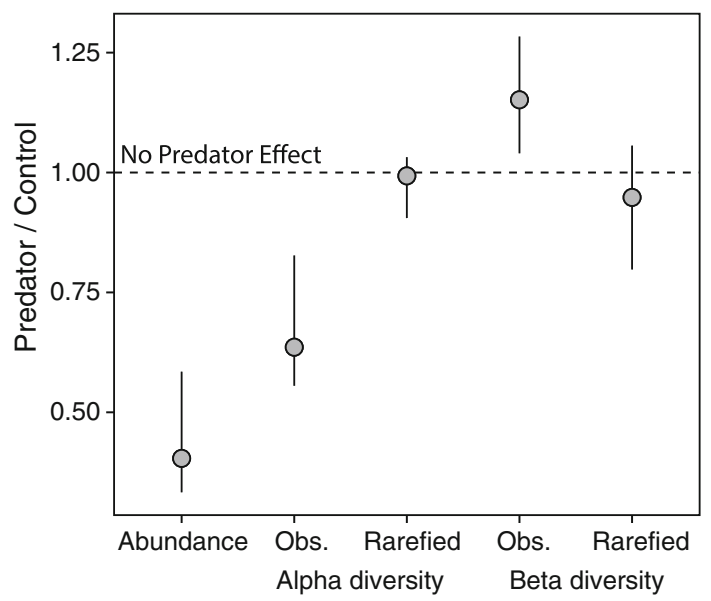

Fig. 2 Mean effects of predators on abundance and diversity (back transformed mean \pm bootstrapped 95\% CI). Effects include abundance, alpha diversity (observed (obs.) and rarefied), and beta diversity measured based on species incidence-Jaccard index (obs. and rarefied). The dashed horizontal line represents no difference between predators and control treatment, values $>1$ represent positive effects of predators, and values $<1$ represent negative effects of predators

increase; $Q=30.989, d f=10, P=0.450$; Fig. 4a), suggesting that mesopredator-induced reductions in prey abundance caused the apparent decline in unrarefied alpha diversity. We found reefs with mesopredators had on average $15 \%$ higher beta diversity $(Q=19.192, d f=10$, $P=0.007$; Figs. 2, 3b), but that these effects similarly disappeared following rarefaction, with no detectible shift in rarefied beta diversity (5\% decrease; $Q=28.902$, $d f=10, P=0.439$; Figs. 2, 4b). Thus, the reef mesopredators measured here were, on average, generalist predators that had strong negative effects on prey abundance and consequently altered patterns of alpha and beta diversity via a statistical sampling effect.

Our results suggest that mesopredators primarily affected prey diversity by reducing prey abundance (Fig. 3a). There were, however, two notable predator species that disproportionately affected rare prey species and significantly lowered rarefied diversity: the dottyback Pseudochromis fuscus (Almany et al. 2007) and peacock grouper Cephalopholis argus (Stier et al. 2014). From a conservation perspective, this disproportionate effect on rare species is particularly concerning in the case of the peacock grouper, because this non-native mesopredator, introduced to Hawaii in the mid-1950s, now constitutes more than $80 \%$ of the large piscivore biomass in some locations (Meyer and Dierking 2011). The unique effects of these two species suggest we need to further study the foraging behavior of mesopredators and in particular their functional responses (sensu Stier et al. 2013a; Stier and White 2014), because predators with a preference for rare species and a Type I or II functional response can

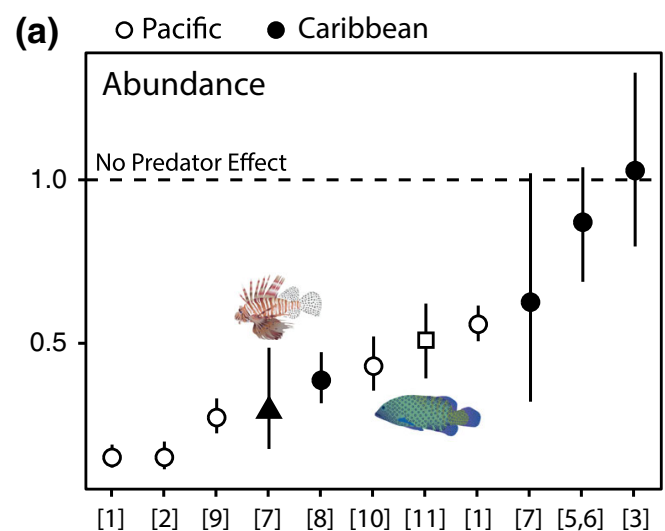

(b)

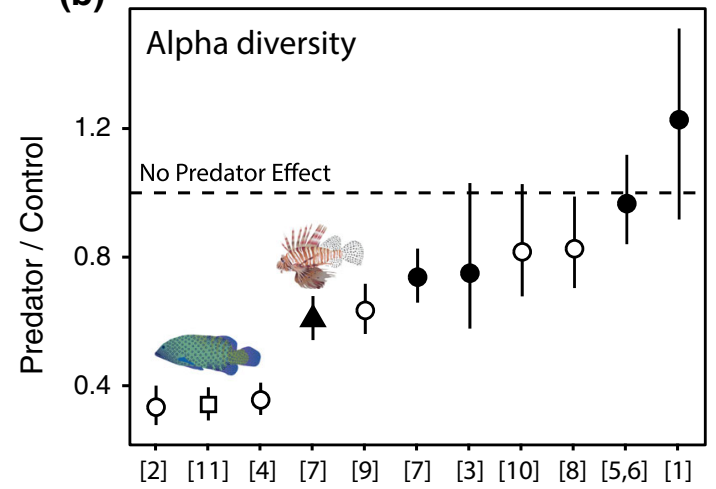

(c)

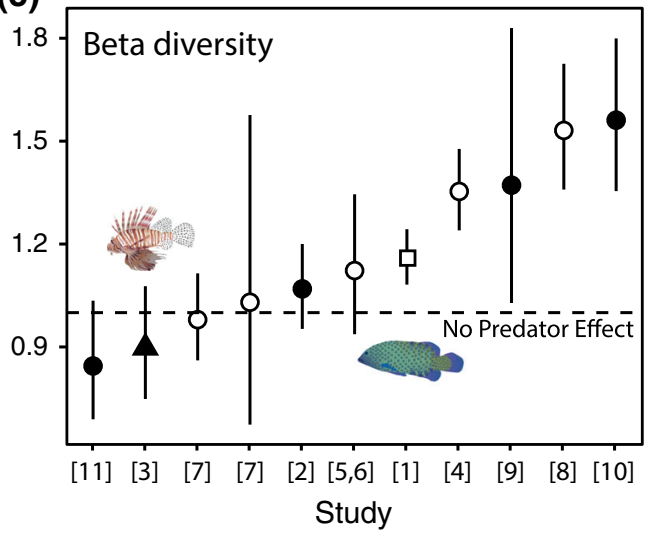

Fig. 3 Distribution of median predator effects ( $\pm 95 \%$ bootstrapped confidence limits) on abundance (a), alpha diversity (b), and beta diversity (c). Dashed horizontal line represents no-predator effect, and point color depicts Caribbean (black) and Pacific (white) studies. Lionfish silhouette (triangle) corresponds to effect measured from Albins (2013), and peacock grouper silhouette (square) corresponds to effect measured from Stier et al. (2014). Studies ranked by magnitude of effect, with strongest negative effects on left and strongest positive effects on right. Numbers correspond to reference numbers listed in ESM Table S1

destabilize prey population dynamics and catalyze reductions in reef biodiversity (White et al. 2010).

Our study also provides insight into the effects of lionfishes in the western Atlantic. The recent invasion and exponential growth of lionfishes in the Atlantic from the 


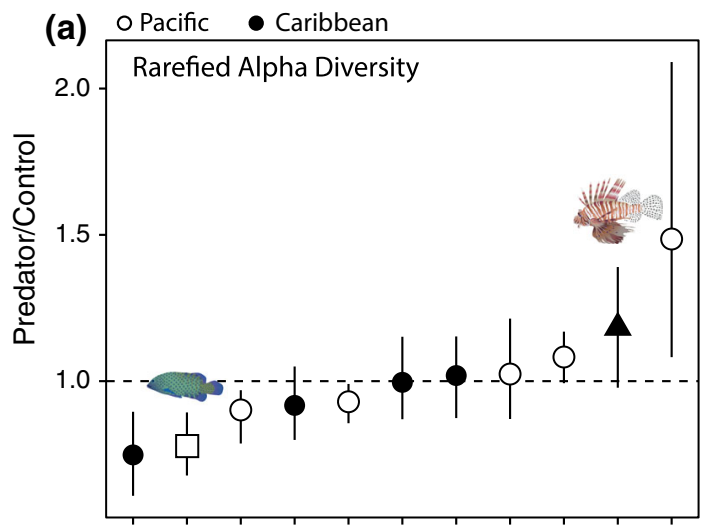

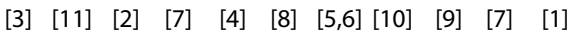

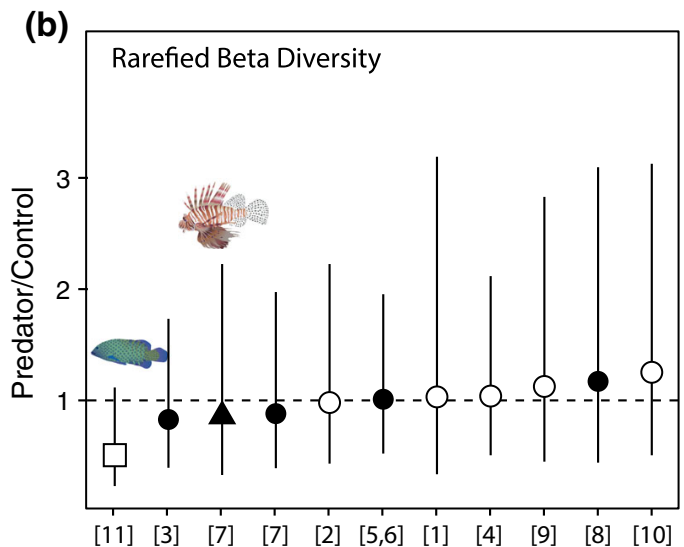

Fig. 4 Distribution of mean predator effects (95\% bootstrapped confidence intervals) across studies ranked by strength of effect from left to right (strongest negative to positive effects). Dashed horizontal line represents no-predator effect on rarefied alpha diversity (species richness (a), and rarefied beta diversity (Jaccard index) (b). Lionfish silhouette and triangle correspond to effect measured from Albins (2013), and peacock grouper silhouette and square correspond to effect measured from Stier et al. (2014). Point color corresponds to ocean basin: Caribbean (black) and Pacific (white). Study number corresponds to reference numbers in ESM Table S1

central US to South America have generated widespread concern for their effects on the prey fish community. The effects of lionfish on abundance and diversity fell within the distribution of predator effects observed across all studies, but was the strongest effect measured in the region (Fig. 3). Rarefaction suggested that lionfish are generalists rather than disproportionately affecting common or rare species (Fig. 4). Therefore, in contrast to the peacock grouper, lionfish may be less likely to threaten prey biodiversity unless they drive prey to such low abundances that they are sensitive to extinction due to demographic stochasticity (sensu Rocha et al. 2015; Ingeman 2016). Such an outcome is likely in some locations based on the strong negative effects of lionfish on a wide variety of native prey species (Albins 2013). Of course, there are also additional biological and socio-economic concerns associated with the lionfish invasion that extend beyond biodiversity effects.

Biodiversity can be associated with ecosystem functioning, productivity, and evolutionary dynamics in marine systems (Gamfeldt et al. 2015). The studies synthesized here offer key insights into how mesopredators affect prey fish abundance and biodiversity and, more broadly, the role mesopredators play in driving spatio-temporal variation in reef-fish biodiversity. However, a number of questions remain unanswered about the role of predation in driving reef-fish assembly, such as: (1) How do these small spatial scale and short temporal scale studies scale up to population and community dynamics on contiguous reefs over longer periods of time? (2) How do the effects of predators on prey community structure cascade to affect the benthic community (Casey et al. 2016)? (3) How do cooperative and antagonistic interactions within and among predator species modify the effect of predators on community structure? As humans continue to alter marine ecosystems through a variety of stressors, a deeper understanding of how invasive predators drive ecosystem structure and function will provide much needed detail to improve conservation and management.

Acknowledgements We are particularly grateful for Glenn Almany's contributions to this project. Unfortunately, Glenn passed away before the manuscript could be completed; therefore, in addition to his intellectual contribution, we also dedicate this manuscript in memoriam to Glenn Almany, his friends, and his family. Many of the projects synthesized above were conducted on Lee Stocking Island in the Bahamas and would not have been possible without the tireless efforts of the employees there whose work ethic inspires us to this day. We thank Kalik, Kerleans, all of the station managers, chefs, mechanics, and field technicians that made this work possible.

\section{References}

Albins MA (2013) Effects of invasive Pacific red lionfish Pterois volitans versus a native predator on Bahamian coral-reef fish communities. Biol Invasions 15:29-43

Almany GR, Webster MS (2006) The predation gauntlet: early postsettlement mortality in reef fishes. Coral Reefs 25:19-22

Almany GR, Peacock LF, Syms C, McCormick MI, Jones GP (2007) Predators target rare prey in coral reef fish assemblages. Oecologia 152:751-761

Anderson MJ, Ellingsen KE, McArdle BH (2006) Multivariate dispersion as a measure of beta diversity. Ecol Lett 9:683-693

Cardoso P, Borges PA, Veech JA (2009) Testing the performance of beta diversity measures based on incidence data: the robustness to undersampling. Divers Distrib 15:1081-1090

Casey JM, Baird AH, Brandl SJ, Hoogenboom MO, Rizzari JR, Frisch AJ, Mirbach CE, Connolly SR (2016) A test of trophic cascade theory: fish and benthic assemblages across a predator density gradient on coral reefs. Oecologia. doi:10.1007/s00442016-3753-8

Côté IM, Green SJ, Hixon MA (2013) Predatory fish invaders: insights from Indo-Pacific lionfish in the western Atlantic and Caribbean. Biol Conserv 164:50-61 
Crooks KR, Soulé ME (1999) Mesopredator release and avifaunal extinctions in a fragmented system. Nature 400:563-566

DeMartini EE, Smith JE (2015) Effects of fishing on the fishes and habitat of coral reefs. In: Mora C (ed.) Ecology of fishes on coral reefs. Cambridge University Press, Cambridge, UK, pp135

Estes JA, Terborgh J, Brashares JS, Power ME, Berger J, Bond WJ, Carpenter SR, Essington TE, Holt RD, Jackson JBC, Marquis RJ, Oksanen L, Oksanen T, Paine RT, Pikitch EK, Ripple WJ, Sandin SA, Scheffer M, Schoener TW, Shurin JB, Sinclair ARE, Soulé ME, Virtanen R, Wardle DA (2011) Trophic downgrading of planet earth. Science 333:301-306

Gamfeldt L, Lefcheck JS, Byrnes JE, Cardinale BJ, Duffy JE, Griffin JN (2015) Marine biodiversity and ecosystem functioning: what's known and what's next? Oikos 124:252-265

Goatley CHR, Bellwood DR (2016) Body size and mortality rates in coral reef fishes: a three-phase relationship. Proc R Soc Lond B Biol Sci 283:20161858

Gotelli NJ, Colwell RK (2001) Quantifying biodiversity: procedures and pitfalls in the measurement and comparison of species richness. Ecol Lett 4:379-391

Hedges LV, Gurevitch J, Curtis PS (1999) The meta-analysis of response ratios in experimental ecology. Ecology 80:1150-1156

Hixon MA (1991) Predation as a process structuring coral reef fish communities. In: Sale PF (ed) The ecology of fishes on coral reefs. Academic Press, San Diego, pp 475-508

Hixon MA (2015) Predation: piscivory and the ecology of coral-reef fishes. In: Mora C (ed) Ecology and conservation of fishes on coral reefs: the functioning of an ecosystem in a changing world. Cambridge University Press, Cambridge, pp 41-54

Ingeman KE (2016) Lionfish cause increased mortality rates and drive local extirpation of native prey. Mar Ecol Prog Ser 558:235-245

Meyer A, Dierking J (2011) Elevated size and body condition and altered feeding ecology of the grouper Cephalopholis argus in non-native habitats. Mar Ecol Prog Ser 439:203-212

Osenberg CW, Sarnelle O, Cooper SD, Holt RD (1999) Resolving ecological questions through meta-analysis: goals, metrics, and models. Ecology 80:1105-1117
Prugh LR, Stoner CJ, Epps CW, Bean WT, Ripple WJ, Laliberte AS, Brashares JS (2009) The rise of the mesopredator. Bioscience 59:779-791

R Development Core Team (2013) R: a language and environment for statistical computing. R Foundation for Statistical Computing, Vienna

Ritchie EG, Johnson CN (2009) Predator interactions, mesopredator release and biodiversity conservation. Ecol Lett 12:982-998

Rocha LA, Rocha CR, Baldwin CC, Weigt LA, McField M (2015) Invasive lionfish preying on critically endangered reef fish. Coral Reefs 34:803-806

Sogard SM (1997) Size-selective mortality in the juvenile stage of teleost fishes: a review. Bull Mar Sci 60:1129-1157

Stallings CD (2009) Fishery-independent data reveal negative effect of human population density on Caribbean predatory fish communities. PLoS One 4:e5333

Stier A, White JW (2014) Predator density and the functional responses of coral reef fish. Coral Reefs 33:235-240

Stier AC, Geange SW, Bolker BM (2013a) Predator density and competition modify the benefits of group formation in a shoaling reef fish. Oikos 122:171-178

Stier AC, Bolker BM, Osenberg CW (2016) Using rarefaction to isolate the effects of patch size and sampling effort on beta diversity. Ecosphere 7:e01612

Stier AC, Geange SW, Hanson KM, Bolker BM (2013b) Predator density and timing of arrival affect reef fish community assembly. Ecology 94:1057-1068

Stier AC, Hanson KM, Holbrook SJ, Schmitt RJ, Brooks AJ (2014) Predation and landscape characteristics independently affect reef fish community organization. Ecology 95:1294-1307

Viechtbauer W (2010) Conducting meta-analyses in $\mathrm{R}$ with the metafor package. J Stat Softw 36:1-48

White JW, Samhouri JF, Stier AC, Wormald CL, Hamilton SL, Sandin SA (2010) Synthesizing mechanisms of density dependence in reef fishes: behavior, habitat configuration, and observational scale. Ecology 91:1949-1961 


\section{ESM 1}

Table S1 Focal studies, species, and study durations. Note that Albins (2013) examined Pterois volitans and Cephalopholis fulva independently and each species is plotted separately in the main text. All other studies listed below examined either a single predator effect or the combined effect of multiple predator species

\begin{tabular}{|c|c|c|c|}
\hline Predator Species & $\begin{array}{l}\text { Duration } \\
\text { (days) }\end{array}$ & Reference & $\begin{array}{l}\text { Reference } \\
\text { No. }\end{array}$ \\
\hline Cephalopholis boenak; Pseudochromis fuscus & 50 & $\begin{array}{l}\text { (Webster and } \\
\text { Almany 2002) }\end{array}$ & 1 \\
\hline Cephalopholis boenak; Pseudochromis fuscus & 42 & (Webster 2002) & 2 \\
\hline $\begin{array}{l}\text { Cephalopholis cruentata; Cephalopholis } \\
\text { fulva; Epinephelus striatus; Gymnothorax } \\
\text { moringa; Gymnothorax vicinus }\end{array}$ & 44 & (Almany 2003) & 3 \\
\hline Cephalopholis boenak; Pseudochromis fuscus & 50 & $\begin{array}{l}\text { (Almany } \\
\text { 2004a) }\end{array}$ & 4 \\
\hline $\begin{array}{l}\text { Cephalopholis cruentata; Epinephelus } \\
\text { striatus; Serranus tigrinus; Rypticus } \\
\text { bistrispinus; Gymnothorax moringa; } \\
\text { Gymnothorax vicinus }\end{array}$ & 60 & $\begin{array}{l}\text { (Almany } \\
\text { 2004b; Almany } \\
\text { 2004c) }\end{array}$ & 5,6 \\
\hline Pterois volitans; Cephalopholis fulva & 70 & (Albins 2013) & 7 \\
\hline Cephalopholis fulva; Cephalopholis cruentata & 52 & $\begin{array}{l}\text { (Stallings } \\
\text { 2009) }\end{array}$ & 8 \\
\hline $\begin{array}{l}\text { Balistapus undulatus; Rhinecanthus aculeatus; } \\
\text { Bothus spp.; Caranx melampygus; } \\
\text { Halichoeres hortulanus; Halichoeres } \\
\text { trimaculatus; Lethrinus olivaceus; Parapercis } \\
\text { spp; Pterois radiata; Epinephelus merra; } \\
\text { Synodus spp. }\end{array}$ & 54 & $\begin{array}{l}\text { (Heinlein et al. } \\
\text { 2010) }\end{array}$ & 9 \\
\hline Paracirrhites arcatus & 120 & $\begin{array}{l}\text { (Stier et al. } \\
\text { 2013) }\end{array}$ & 10 \\
\hline Cephalopholis argus & 60 & $\begin{array}{l}\text { (Stier et al. } \\
2014 \text { ) }\end{array}$ & 11 \\
\hline
\end{tabular}




\section{ESM 2: Rarefaction methods}

Estimates of species richness and beta diversity can be sensitive to differences in overall abundance within and among patches (Gotelli and Colwell 2001; Cardoso et al. 2009). Because predators reduce prey abundance, we expected that they would also reduce species richness, either through frequency dependent foraging (in particular, the preferential consumption of rare species) or simply by reducing overall density (i.e., a sampling effect). If predators were primarily generalists, reducing overall density, then among-treatment differences in species richness would subside after rarefaction (Almany and Webster 2004). Individual-based rarefaction has classically been used to adjust species richness estimates for differences in abundance of organisms across sites by estimating the mean species richness in repeated subsamples from each site (Gotelli and Colwell 2001). Although the importance of bias in species richness estimates due to differential sample sizes across treatments has been previously recognized, its effect on estimates of beta diversity is less clear. Developing estimates of differences in beta diversity that account for differences in sample size is particularly important in empirical ecology, where manipulating a given ecological factor with a focus on changes in species diversity often leads to concurrent shifts in the number of individuals. For example, in this study, experimental reefs with predators tended to have approximately half as many fish as reefs without predators. Here, we conducted individual-based rarefaction to estimate rarefied alpha diversity and beta diversity that ensured that the number of individuals sampled was comparable across reefs and treatments. For additional details on the methodology see: (Stier et al. 2013; Stier et al. 2014; Stier et al. 2016).

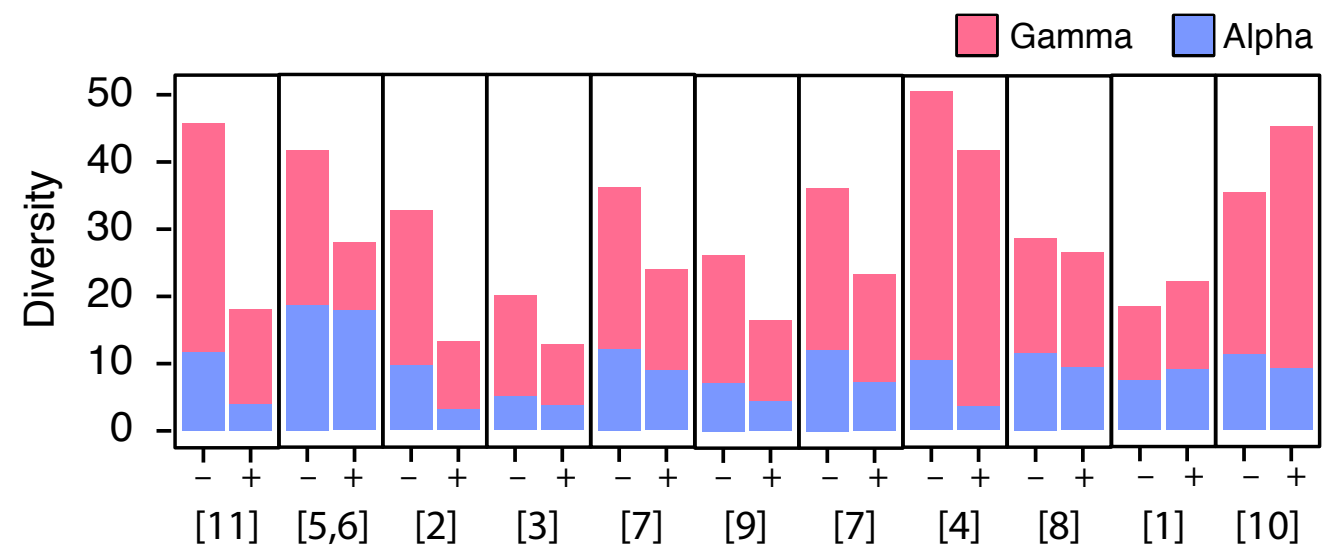

ESM Fig. S1 Distribution of predator effects on gamma (pink) and alpha (blue) diversity across studies ranked by strength of predator effect on gamma diversity. Predator present treatments are marked as + and predator absent treatments are marked as -. Numbers correspond to reference number and species in Table S1

\section{References}


Albins MA (2013) Effects of invasive Pacific red lionfish Pterois volitans versus a native predator on Bahamian coral-reef fish communities. Biological Invasions 15:29-43

Almany GR (2003) Priority effects in coral reef fish communities. Ecology 84:1920-1935

Almany GR (2004a) Priority effects in coral reef fish communities of the Great Barrier Reef. Ecology $85: 2872-2880$

Almany GR (2004b) Does increased habitat complexity reduce predation and competition in coral reef fish assemblages? Oikos 106:275-284

Almany GR (2004c) Differential effects of habitat complexity, predators and competitors on abundance of juvenile and adult coral reef fishes. Oecologia 141:105-113

Almany GR, Webster MS (2004) Odd species out as predators reduce diversity of coral-reef fishes. Ecology 85:2933-2937

Cardoso P, Borges PA, Veech JA (2009) Testing the performance of beta diversity measures based on incidence data: the robustness to undersampling. Diversity and Distributions 15:1081-1090

Gotelli NJ, Colwell RK (2001) Quantifying biodiversity: procedures and pitfalls in the measurement and comparison of species richness. Ecology Letters 4:379-391

Heinlein JM, Stier AC, Steele MA (2010) Predators reduce abundance and species richness of coral reef fish recruits via non-selective predation. Coral Reefs 29:527-532

Stallings CD (2009) Predator identity and recruitment of coral-reef fishes: indirect effects of fishing. Marine Ecology-Progress Series 383:251-259

Stier AC, Bolker BM, Osenberg CW (2016) Using rarefaction to isolate the effects of patch size and sampling effort on beta diversity. Ecosphere 7:e01612-n/a

Stier AC, Geange SW, Hanson KM, Bolker BM (2013) Predator density and timing of arrival affect reef fish community assembly. Ecology 94:1057-1068

Stier AC, Hanson KM, Holbrook SJ, Schmitt RJ, Brooks AJ (2014) Predation and landscape characteristics independently affect reef fish community organization. Ecology 95:1294-1307

Webster MS (2002) Role of predators in the early post-settlement demography of coral reef fishes. Oecologia 131:52-60

Webster MS, Almany GR (2002) Positive indirect effects in a coral reef fish community. Ecology Letters 5:549-557 